\title{
Conjunto monetal de Sancti Petri. Estudio evolutivo y tratamiento de los procesos de alteración
}

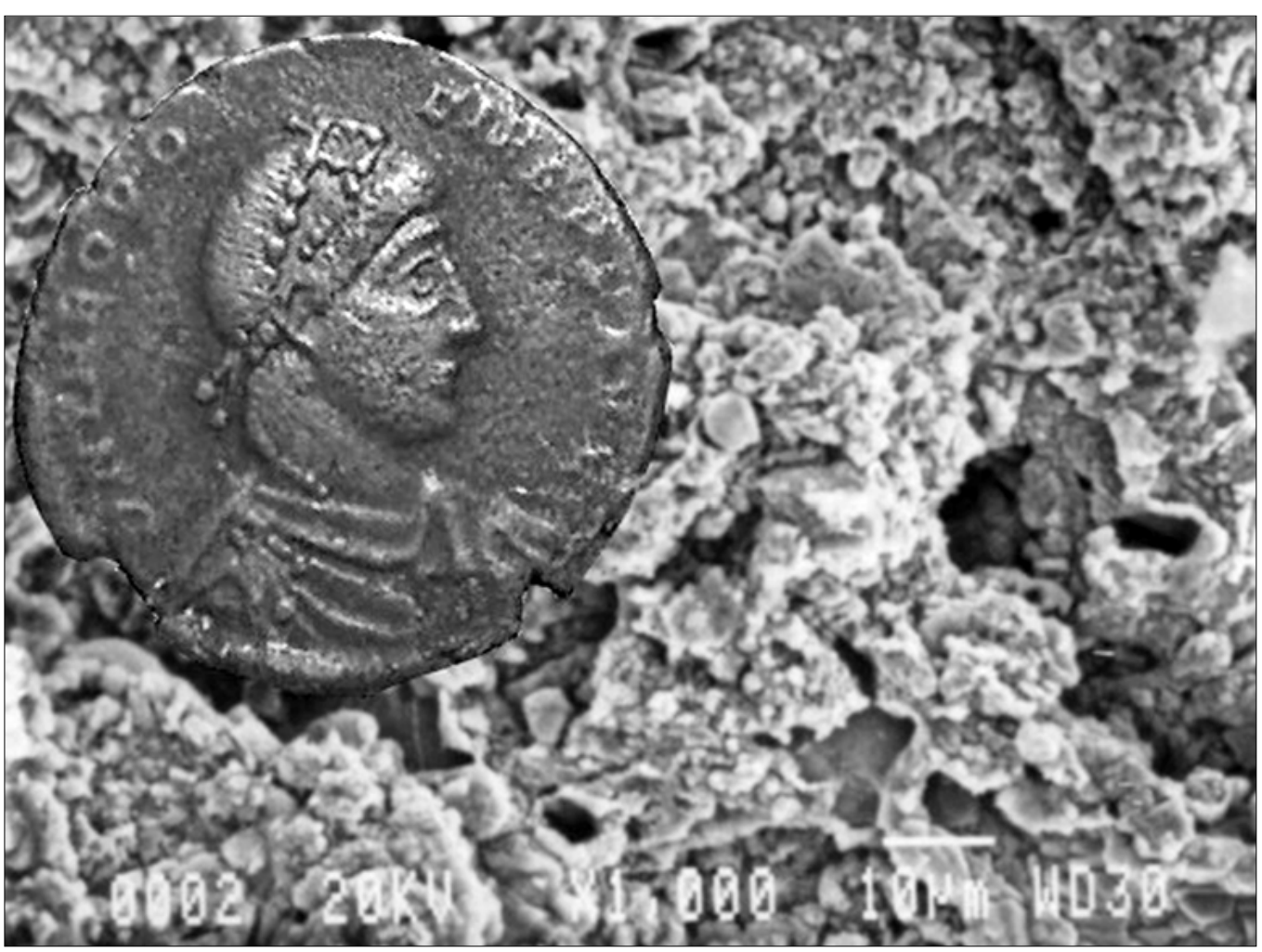

Manuel Bethencourt Núñez Luis Carlos Zambrano Valdivia

Centro de Arqueología Subacuática del IAPH

\section{Resumen}

En este artículo se expone el tratamiento de conservación aplicado sobre el primer grupo de monedas correspondiente a la prospección del año 1998 que aportó un total de 56 objetos de naturaleza metálica. Por otra parte, técnicas complementarias como microscopia electrónica de barrido (SEM) y espectroscopia de energía dispersiva (EDS), han permitido realizar un análisis detallado de los productos de corrosión depositados, a partir de los cuales se ha realizado un estudio evolutivo de los distintos procesos de alteración que pudieron sufrir las monedas desde la fase de abandono hasta la de recuperación.
Palabras clave:

Corrosión/ estabilización/ cloruros/ cobre/ conservación/ monedas/ alteración.

\section{Introducción}

Un conjunto de 61 monedas de época bajo-imperial fueron recuperadas en el transcurso de las actuaciones arqueológicas de prospección realizadas en el área de Sancti Petri. De este conjunto, 55 piezas han sido tratadas en los laboratorios y talleres del Centro de Arqueología Subacuática del IAPH con el objeto de permitir su estudio y asegurar la permanencia frente a la corrosión. Para alcanzar estos objetivos se han aplicado, básicamente, dos tratamientos de conservación activa: "desconcreción" o remoción de las concreciones minerales, y "decloruración" o extracción de aniones $\mathrm{Cl}$-. 
Del material recuperado en Sancti Petri se ha distinguido un grupo de 55 piezas en función del tratamiento aplicado. Se trata de 55 monedas, más una hebilla de latón, que fueron recuperadas en el trascurso de las prospecciones del año 1998. Sobre este grupo de objetos se ha desarrollado un tratamiento de "desconcreción" no-documentado en fecha sin precisar. Careciendo de estos datos, el informe actual se remite a las intervenciones realizadas partir de la fase de estabilización, -remoción de cloruros-. En la caracterización de este material se ha supuesto un cuadro de alteración similar a las piezas recuperadas en la prospección del año 1999.

Por consiguiente, en este artículo se expone el tratamiento de conservación aplicado sobre el grupo de monedas correspondiente a la prospección del año 1998 que aportó un total de 56 objetos de naturaleza metálica. Por otra parte, se exponen una serie de técnicas complementarias como la microscopia electrónica de barrido (SEM) y la espectroscopia de energía dispersiva (EDS), que han permitido realizar un análisis detallado de los productos de corrosión depositados, a partir de los cuales se ha elaborado un estudio evolutivo de los distintos procesos de alteración que pudieron sufrir las monedas desde la fase de abandono hasta la de recuperación.

\section{Cuadro de alteración}

La caracterización del material, en cuanto a su estado de conservación, responde a un cuadro de alteración típico de las aleaciones cupríferas en el medio aeróbico. Las piezas presentan un tipo de corrosión uniforme caracterizada por la pérdida regular de la superficie metálica (figura I).

Esta es la forma más común de corrosión a la que están sujetos la mayoría de los metales cupríferos en medios aerobios. En el caso particular de este conjunto monetario existe un cuadro de alteración homogéneo caracterizado por unos productos de corrosión carbonatados en superficie -azurita y malaquita-, observados de visu como primera fase más externa de corrosión (figura 2). Siendo estos productos característicos de la combinación entre metales aleados en cobre y medios acuáticos bien oxigenados. Bajo esta primera fase de carbonatos existe una capa fina de óxidos directamente adherida a la superficie metálica. Se trata de cuprita - $\mathrm{CuO}$ - identificable de visu por su coloración anaranjada. Inmediatamente debajo se conserva el núcleo metálico del objeto, en la mayoría de los casos, con escasa pérdida de materia. Pueden reconocerse de visu las marcas impresas en los anversos y reversos de las monedas.

Partiendo de una observación detallada, es posible interpretar el proceso de abandono y la consiguiente degradación de los objetos hallados en Sancti Petri. Pese a que evidentemente nos encontramos ante una aleación de cobre, la composición original de la misma es desconocida. Se denomina bronce a una aleación de cobre cuyo aleante mayoritario es el estaño, pudiendo incluir en menor proporción zinc. Si la cantidad de zinc es mayor que la de estaño, se denominará latón. Muchas veces la división entre latón y bronce no está clara, encontrándose en ocasiones ambos elementos en una misma proporción.

Tras un periodo tan prolongado de exposición al medio marino, el proceso de corrosión más característico en las aleaciones de cobre es la disolución selectiva de los aleantes. Así, el bronce sufre desestanificación o disolución selectiva del estaño mientras que en el latón se produce la deszincnificación o disolución selectiva del zinc. En esta forma de corrosión, el estaño o zinc que se encuentran en la aleación se eliminan de forma selectiva y la aleación se transforma en una masa porosa de cobre con una baja resistencia mecánica pero que generalmente retiene la forma original del objeto. Pese a que este proceso se puede dar tanto en medios aerobios como anaerobios, es en estos últimos donde la disolución selectiva se muestra con mayor intensidad.

Existen pocos estudios que detallen los productos de corrosión de los aleantes que aparecen en estas aleaciones tras periodos prolongados en medio marino, pero son predominantemente compuestos de estaño y oxígeno en forma de óxidos e hidróxidos. El análisis

Figura 1. Esquema ilustrativo sobre la alteración de aleaciones cupríferas en medio aeróbico con pérdida regular de la superficie metálica. En el primer cuadro hay una moneda recién acuñada con aristas "vivas" y un relieve nítido. La misma moneda ha sufrido un proceso de corrosión donde se suavizan los contornos por la pérdida de materia.
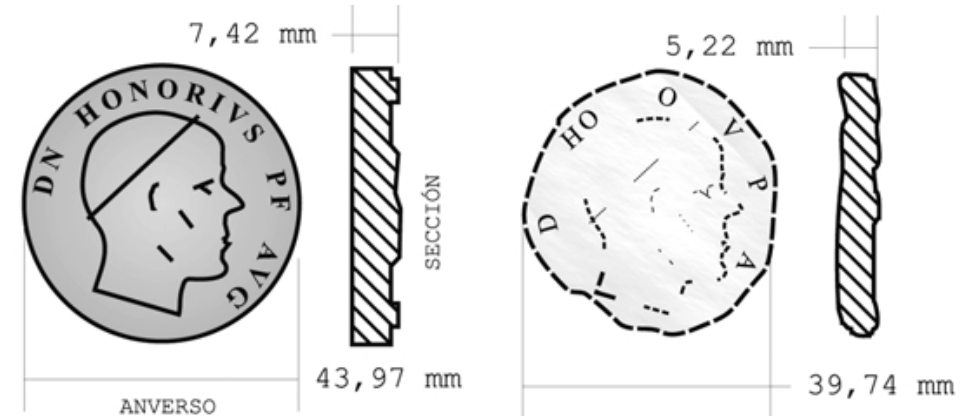

Figura 2. Esquema elemental de la superposición de estratos característica de los procesos de corrosión de aleaciones cupríferas en medio aeróbico según análisis de visu.

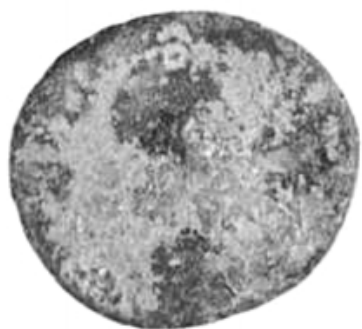

Anverso

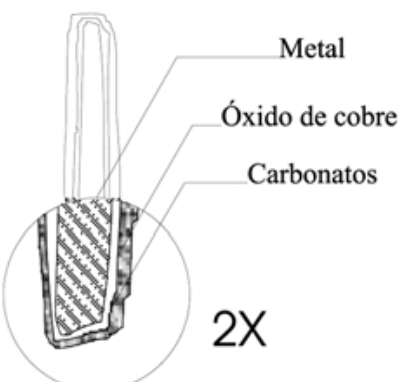

Sección 


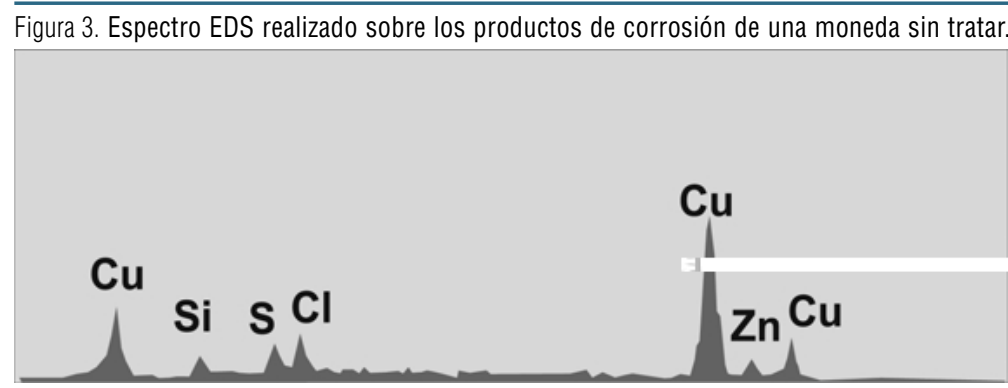

Figura 4. Fotografía e imagen SEM de una moneda sin tratar cubierta de productos de corrosión.

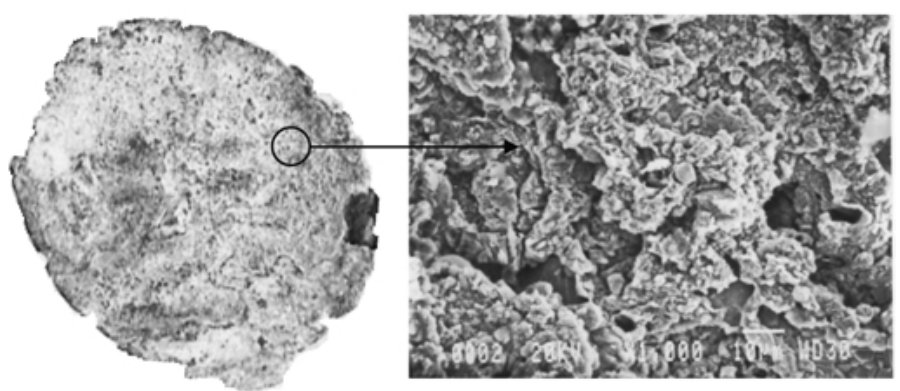

Figura 5. Espectro EDS realizado sobre zona libre de productos de corrosión en una moneda tras el tratamiento de estabilización.

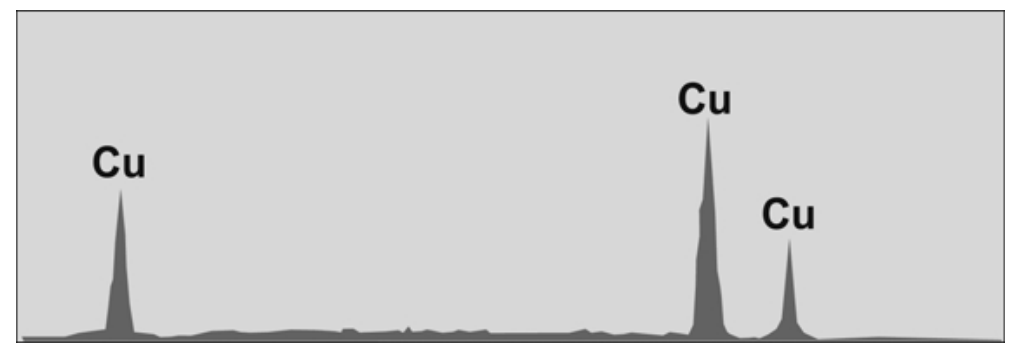

Figura 6. Fotografía e imágenes SEM de una moneda sin productos de corrosión tras el tratamiento de estabilización.

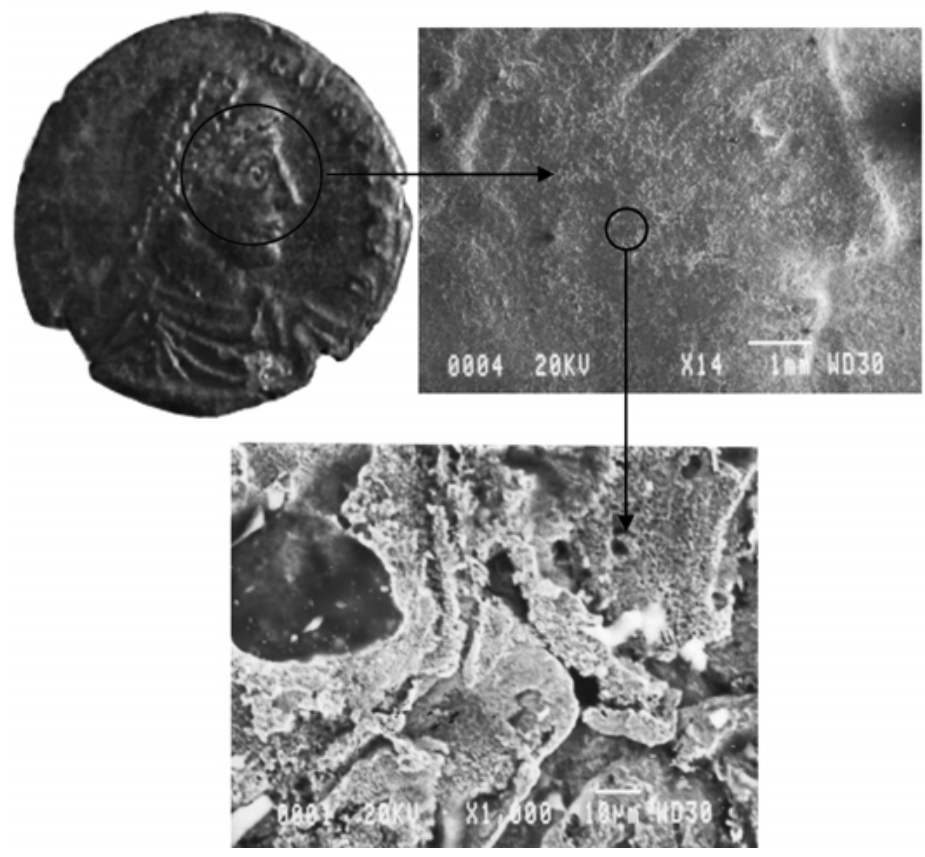

de los espectros EDS permite certificar la existencia del proceso de disolución selectiva. Así, en la figura 3 se muestra un espectro EDS realizado sobre el óxido verde depositado sobre una de las monedas, figura 4. En el mismo se observa la presencia lógica del cobre, así como evidencias de la existencia de azufre, cloro, silicio y zinc. Sin embargo no se observan evidencias de estaño. Mientras, la figura 5 muestra un espectro EDS realizado sobre una porción libre de óxidos de una moneda tras el tratamiento de estabilización, figura 6. En el mismo se observa exclusivamente la presencia de cobre, sin trazas de estaño o zinc.

La química del estaño en disoluciones alcalinas o neutras está dominada por la formación de óxidos o hidróxidos estables e insolubles. A pH de agua de mar, entre 7,8 y 8,3 , los productos de corrosión del estaño permanecen sobre el objeto y suelen conservar el aspecto del mismo. La no aparición de estaño sobre la superficie metálica o en el óxido puede responder a dos motivos. Por un lado a su inexistencia en la aleación original. La datación del tesorillo (siglo IV dC.) corresponde con una época en la que el latón podía sustituir al bronce en el acuñamiento de monedas (R.F. Tylecote, 1977, A. France-Lanord, 1980), pese a que lo más usual era el empleo de aleaciones ternarias Cu-SnZn. Otra posibilidad sería que los productos de corrosión con estaño, originados en los primeros estadios de exposición al medio, hubiesen desaparecido como consecuencia de los procesos erosivos a los que se veían expuestas las monedas en el momento de su localización. Así, cabe destacar la presencia de inclusiones de silicio en la matriz metálica, probablemente provenientes del impacto de las arenas. En la figura 7 se muestra un espectro EDS realizado sobre un grano de silicio.

En cuanto al zinc, hay que indicar que debido a su gran solubilidad, sus compuestos no se suelen encontrar en los productos de corrosión, y si están presentes, se encuentran atrapados en la matriz de la concreción. El zinc mostrado en la figura 3 bien podría corresponder a trazas de este elemento sobre el depósito analizado.

Por último, es interesante destacar la presencia de azufre en el espectro mostrado en la figura 3. En medios anaeróbios, los productos de corrosión del cobre están dominados por iones sulfuro como calcocita $\left(\mathrm{Cu}_{2} \mathrm{~S}\right)$ y covellita (CuS). En estos medios, una vez que el oxígeno se ha consumido, la principal reacción catódica será la de evolución de hidrógeno estimulada por la presencia de bacterias sulfato reductoras. Los iones sulfuro producidos por estas bacterias forman sulfuros de cobre con los iones cobre provenientes de la corrosión del metal. Estos sulfuros de cobre forman una película adherente y protectora sobre el metal base. La calcocita es estable en un amplio rango de $\mathrm{pH}$ y Eh, mientras que la región de estabilidad de la covellita es mucho menor.

Esto estaría en contraposición con el cuadro de alteración que mostraban las monedas en el momento de su extracción, típico de aleaciones de cobre sumergidas en medio aerobio, y caracterizado por una corro- 
sión uniforme y la presencia en superficie de azurita $\left(\mathrm{Cu}_{3}(\mathrm{OH})_{2}\left(\mathrm{CO}_{3}\right)_{2}\right)$ y malaquita $\left(\mathrm{Cu}_{2}(\mathrm{OH})_{2} \mathrm{CO}_{3}\right)$.

Se podría buscar una posible explicación a esta contradicción en los procesos de dinámica litoral y cambios geomorfológicos naturales que afectan a la zona donde fueron localizadas las monedas, el Caño de Sancti Petri (F.J. García, 2000). También existen otros cambios geomorfológicos de origen antrópico. La fuerte dinámica sedimentaria de la zona obliga a continuos dragados de la zona. Inicialmente las monedas pudieron depositarse en un medio anaerobio, bien por el tipo de sedimento, bien por sufrir un rápido enterramiento, figura 8(a). En este periodo las monedas desarrollarían productos de corrosión como calcocita y covellita, figura 8(b). Posteriormente, y dados los continuos cambios en la geomorfología de la zona, las monedas serían expuestas de nuevo a un medio aerobio y a la erosión mecánica impuesta por el medio, figura 8(c). En presencia de oxígeno, la calcocita se puede oxidar a covellita. Con el tiempo, y debido a su baja estabilidad, la mayor parte de la covellita se disolvería, dando paso a los productos de corrosión típicos de zonas aerobias, figura 8 (d). De haber ocurrido así, el proceso de corrosión selectiva del que fuese el o los aleantes mayoritarios se habría desarrollado mayoritariamente en esta fase.

Estos procesos han podido ciclarse a lo largo del periodo de exposición de las monedas al medio marino. Una vez expuestas a un medio aerobio, y debido tanto a la solubilidad del Cu (I) y del Cu (II) como a los procesos erosivos, no se encuentran productos de corrosión basados en sulfatos y bicarbonatos de estos aniones. Sin embargo, en un lugar bien oxigenado, la etapa controlante en la corrosión del cobre es la reducción del oxígeno molecular (L. Giuliani, 1970). Un relativamente alto valor de Eh debido a la presencia de oxígeno tenderá a favorecer la formación de iones Cu (II), y una vez que la concentración en disolución de Cu (II) alcance aproximadamente 10-6 M, precipitará una película protectora de algunos productos como malaquita, tenorita, atacamita o azurita. Como se ha comentado, los productos localizados de visu inicialmente sobre las monedas fueron azurita y malaquita, y de esta forma se explicaría su origen.

\section{Proyecto de intervención}

La intervención del conjunto de objetos recuperados en la prospección del año 1998 está dirigida a conseguir la estabilización de los procesos físico-químicos de corrosión que tras la recuperación son favorecidos por la presencia de cloruros cristalizados en la estructura interna de los mismos.

Los productos de corrosión de aleaciones de cobre provenientes del medio marino contienen gran cantidad de cloruros, generalmente en forma de $\mathrm{CuCl}$, $\mathrm{Cu}_{2}(\mathrm{OH})_{3} \mathrm{Cl}$ o $\mathrm{CuCl}_{2} \cdot 3 \mathrm{Cu}(\mathrm{OH})_{2}$ (C. Person, 1987). Estos compuestos se encuentran tanto en los productos de corrosión superficiales como dentro de grietas pre- sentes en el interior de la matriz metálica. En presencia de humedad y oxígeno, estos productos pueden dar lugar a la activación y desarrollo de graves procesos corrosivos. La prevención de este proceso es la principal meta de la conservación de aleaciones de cobre.

Para ello se debe remover la mayor cantidad de cloruros fuera de los objetos. Este objetivo puede alcanzarse por descomposición de las sales en un baño reactivo donde se liberan los cloruros disueltos. Una de las fórmulas mas empleadas para la disolución de $\mathrm{CuCl}$ en aleaciones cupríferas es la disolución de sesqui-carbonato sódico al 4\% en agua desmineralizada.

Este procedimiento concluye cuando se alcanza un nivel óptimo de estabilización -remoción de clorurosque viene señalado por las gráficas comparativas donde se muestra la evolución del proceso. Llegado a este punto, se procederá a la protección del objeto mediante inhibidores químicos de la corrosión. Estos compuestos o mezclas de compuestos son conocidos por reducir el grado en los procesos de corrosión o

Figura 7. Espectro EDS realizado sobre una inclusión de silicio en la matriz metálica de una moneda.

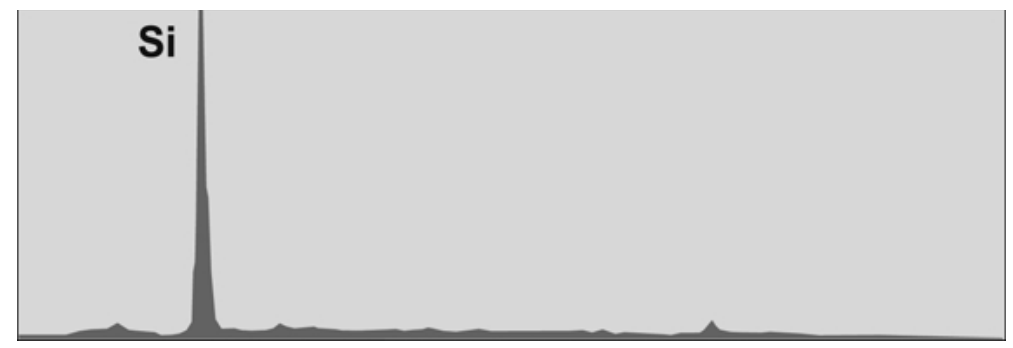

Figura 8. Hipótesis sobre la evolución de los procesos de alteración sufridos por las monedas: (a) fase inicial de abandono, (b) fase anaerobia: formación de covellita y calcocita, (c) fase dinámica: cambios geomorfológicos, (d) fase aerobia: formación de azurita y malaquita.
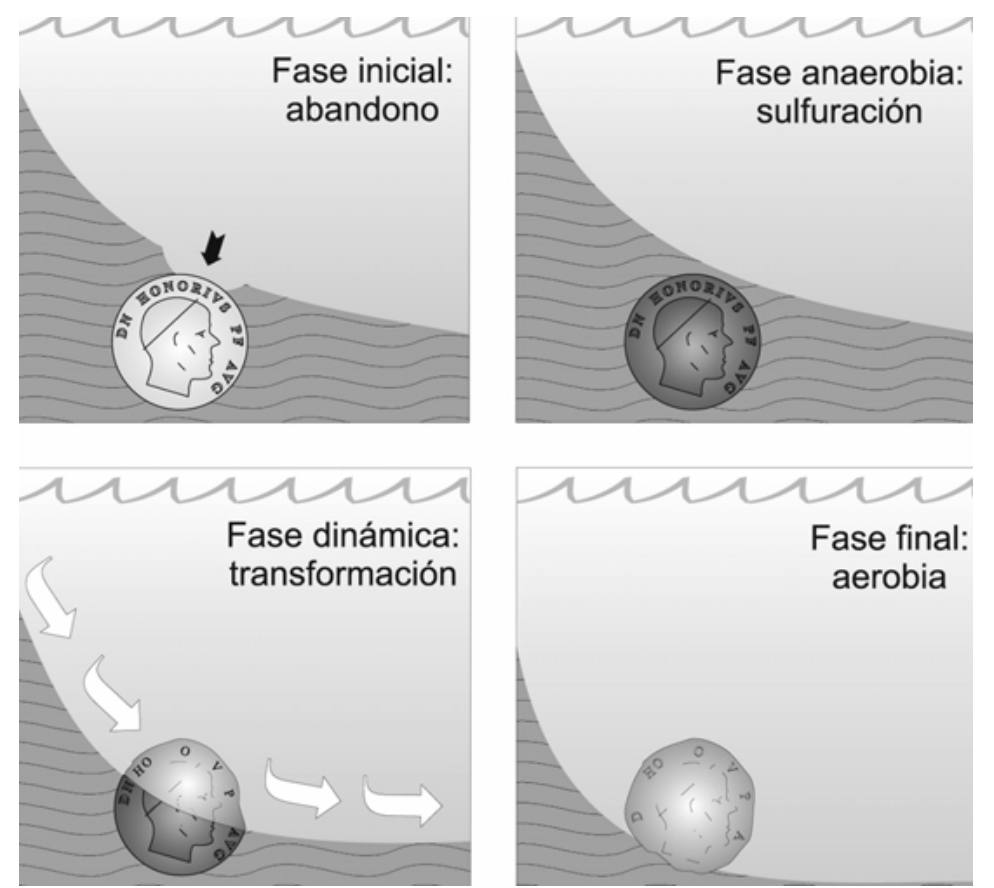
0
0
$+\pi$
2
0
0
0
2
0
0
0
0
0
0
0
2
2
0
1
$<$

\section{Tratamiento}

OBJETIVO: Desengrasado

TÉCNICA: Inmersión en acetona + baño de ultrasonidos DESARROLLO: Previamente a cualquier tratamiento de estabilización sobre objetos ya tratados se precisa efectuar un desengrasado superficial e interno mediante disolventes orgánicos para eliminar posibles capas de protección no-documentadas y favorecer así la difusión de los cloruros. En nuestro caso, los objetos han sido tratados para la remoción de los productos de corrosión y presentan una superficie "limpia" de color anaranjado producida por los óxidos del cobre. La remoción de capas aislantes de naturaleza artificial -resinaso natural -ceras- se realiza mediante inmersión de los objetos en un baño de disolvente cuya acción se favorece por el efecto de un baño de ultrasonidos. Esta operación se desarrolla de un modo paulatino activando el aparto de ultrasonidos en espacios de 5 minutos con intervalos de 15 minutos hasta completar I hora de tratamiento al efecto de no sobrecalentar el objeto ni producir desgaste sobre el mismo.

OBJETIVO; Estabilización de la corrosión.

TÉCNICA; Sesqui carbonato sódico $4 \%$ en agua desmineralizada

DESARROLLO: Este apartado constituye el núcleo del tratamiento de estabilización para la eliminación de los

Figura 9. Gráfico del 1er baño de estabilización en sesqui carbonato sódico $4 \%$. Tiempo total: 21 días. 94,7 miligramos de Cl- extraídos. Fecha de inicio: 5-jun-00. Fecha de fin: 26jun-00. Temperatura media del baño 27,18 grados centígrados. Valor inicial de pH: 9,8. Valor final de pH: 9,89. Valor medio de $\mathrm{pH}: 10,03$. Línea de tendencia de la curva de evolución: $R 2=0,7392$

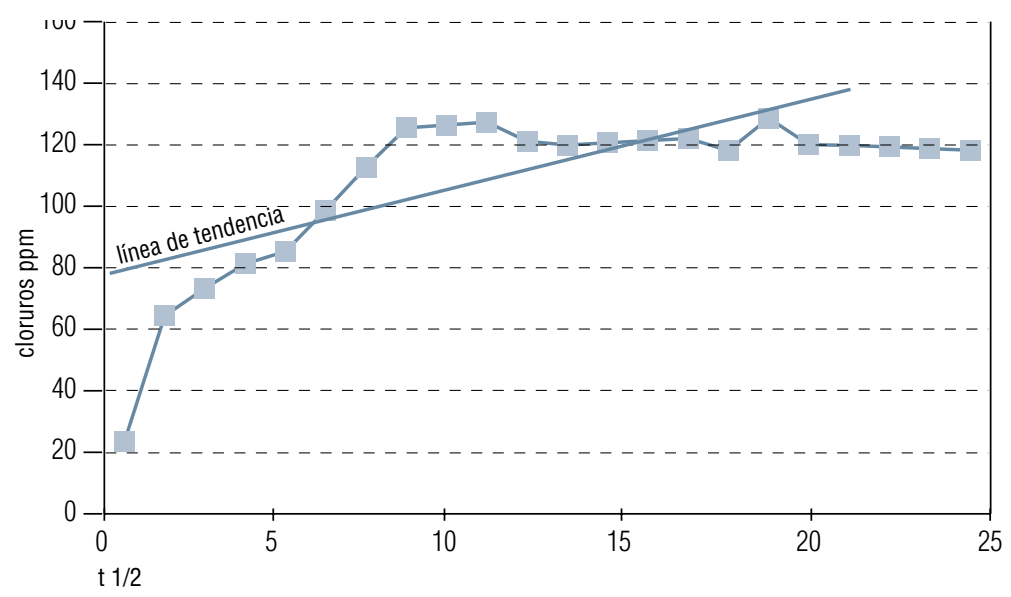

cloruros cuprosos y cúpricos existentes en el interior de la micro-estructura metálica. Para ello se emplea el método de inmersión en una disolución de sesqui-carbonato sódico al $4 \%$ en agua desmineralizada.

Las piezas del conjunto monetal -Sancti Petri 98- se tratan de manera conjunta siendo identificadas para su tratamiento mediante bolsas de red plástica cerradas mediante clips de polipropileno y una etiqueta de papel poliéster donde se anota el número de registro correspondiente. Todas las piezas, un total de 54 , se introducen en una recipiente de polipropileno tapado donde se ha instalado una pequeña bomba de recirculación con caudal constante cuya misión es evitar el estancamiento del reactivo y favorecer la difusión de cloruros fuera del objeto.

El sesqui carbonato sódico se prepara disolviendo en partes iguales $\mathrm{Na}_{2} \mathrm{CO}_{3}$ y $\mathrm{NaHCO}_{3}$ en la proporción del $4 \%$ al peso en agua desmineralizada.

Crucial para la eficiencia y éxito del tratamiento de estabilización es la elección de un buen sistema de medida cuantitativa de cloruros en el baño (D.L. Hamilton, 1976). Existen varios test clásicos, entre los que cabe destacar el método de Mohr y la titración en nitrato de mercurio. En la actualidad existen electrodos selectivos de cloruros que facilitan y reducen la tarea del conservador. En los laboratorios del C.A.S. se emplea un electrodo selectivo de cloruros Metler Toledo, que permite trabajar en un rango de $\mathrm{pH}$ entre 2 y I I. Es importante resaltar que los baños de sesquicarbonato empleados en este trabajo se encontraban a pH próximo a 10. En caso contrario, y dado que se trata de neutralizar un medio básico, se habría empleado $\mathrm{HNO}_{3}$ concentrado añadiéndolo gota a gota, para ajustar el fino con una disolución diluida de este mismo ácido.

Esta técnica permite determinar como progresa la extracción de cloruros mediante medidas cuantitativas de la concentración de cloruros en partes por millón en una muestra de electrolito. El nivel de cloruros en el baño debe medirse regularmente, y conviene representar los datos recogidos en una gráfica que permita visualizar la evolución y eficacia del proceso de limpieza. La medida de cloruros indicará cuando hay que cambiar la disolución del baño y cuando se ha completado el proceso, siempre a criterio del conservador.

El análisis del gráfico de estabilización permite establecer el fin del tratamiento al constatarse una estabilidad en las curvas y unos valores de cloruros por debajo de 50 ppm.

Al objeto de eliminar los depósitos de malaquita formados durante el tratamiento de decloruración, las piezas se han introducido en una disolución de peróxido de hidrógeno - 100 volúmenes, $30 \%$-diluido al 50 $\%$ en agua desmineralizada. El procedimiento ha consistido en introducir las piezas durante I minuto aproximadamente en un recipiente con la citada disolución, apreciándose un ligero burbujeo -evolución de hidrógeno- producido por la reacción del ácido sobre los carbonatos. El efecto es una pátina de color negro -te- 
norita $\mathrm{CuO}_{2}$ - insatisfactoria por disimular las marcas de acuñación. Seguidamente, las piezas son neutralizadas en un baño de agua desmineralizada y mantenidas en una estufa de aire caliente con una humedad relativa inferior al 40\% como medida de conservación preventiva -modificación de la fase húmeda-. La eliminación de depósitos de tenorita se ha realizado mediante inmersión en una disolución de ácido cítrico y tiourea. Para ello se ha preparado una disolución de 10.000 mililitros de agua corriente / 500 gramos de ácido cítrico I y 100 gramos de tiourea. Las piezas han sido introducidas en el baño de tratamiento durante 6 horas. La disolución fresca tiene aproximadamente un $\mathrm{pH}$ de 2 . Después de que el objeto se introduce en el baño con esta disolución el pH alcanza rápidamente valores de 3-4 debido a la neutralización de parte del ácido por los depósitos de carbonatados presentes en el objeto. En este rango de $\mathrm{pH}$ una disolución de ácido cítrico, incluso sin tiourea, tiene poca tendencia a atacar el metal (MerK, L.E., 1978). Tras completarse la limpieza, se han retirado las piezas del baño, permaneciendo durante 24 horas sumergidas en otro baño de agua desmineralizada al objeto de neutralizar el ácido.

OBJETIVO: inhibición de la corrosión

TÉCNICA: Inmersión benzotriazol I\% en agua desmineralizada

DESARROLLO: Como tratamiento inhibidor de la corrosión se ha aplicado sobre los objetos una disolución al $1 \%$ de benzotriazol en agua desmineralizada. La acción inhibidora de la corrosión del BTA sobre las aleaciones de cobre se fundamenta en la formación de una película inerte, estable y polimérica sobre la superficie del cobre y sus productos de corrosión que los aísla de la humedad atmosférica y el oxígeno (Cotton, J.B., 1963). La composición de la película de BTA formada sobre la corrosión del cobre indica una considerable variación dependiendo de factores tales como la composición de los productos de corrosión, la relación entre productos de corrosión-concentración de BTA, y el tipo de disolvente utilizado (Gree-

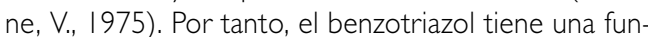
ción aislante sobre el objeto que es susceptible de desarrollar nuevos procesos de corrosión a partir de cloruros internos sin remover. También constituye el BTA una barrera frente a la aportación de cloruros ambientales y humedad cuya combinación desencadena la activación de los procesos corrosivos.

El inhibidor es aplicado sumergiendo el objeto en una disolución diluida de BTA en agua o alcohol. La elección de la disolución acuosa se debe a motivos de toxicidad, ya que la eficacia de ambos tratamientos se ha manifestado similar. Habitualmente se recomienda la aplicación de un vacío parcial en los tratamientos de impregnación con BTA (North, N.A., 1987). aplicado para asegurar que la disolución penetra a través de la pátina o costra hasta alcanzar la nantokita y el núcleo metálico remanente. El único requerimiento previo a la impregnación es el desengrasado del objeto con un disolvente.

Siguiendo estas prescripciones, el conjunto monetario se ha tratado con acetona mediante inmersión en cu-
Figura 10. Gráfico del $2^{0}$ baño de estabilización en sesqui carbonato sódico $4 \%$. Tiempo total: 32 días. 20,41 miligramos de Cl- extraídos. Fecha de inicio: 27-jun-00. Fecha de fin: 29-jul-00. Temperatura media del baño 28,6 grados centígrados. Valor inicial de pH: 9,69. Valor final de pH: 9,99. Valor medio de pH: 9,93. Línea de tendencia de la curva de evolución: $\mathrm{R} 2=0,0531$.

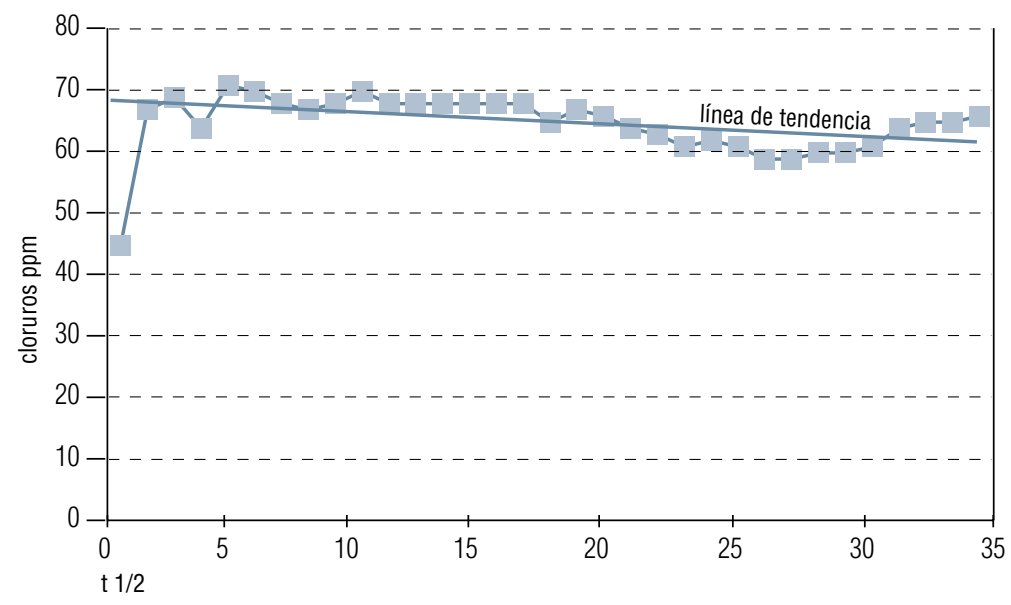

Figura 11. Gráfico del 3er baño de estabilización en sesqui carbonato sódico $4 \%$. Tiempo total: 52 días. 24,78 miligramos de Cl- extraídos. Fecha de inicio: 30 -jul-00. Fecha de fin: 20-sep-00. Temperatura media del baño 28,18 grados centígrados. Valor inicial de $\mathrm{pH}$ : 8,39. Valor final de $\mathrm{pH}: 10,2$. Valor medio de pH: 9,98. Línea de tendencia de la curva de evolución: $R 2=0,6664$.

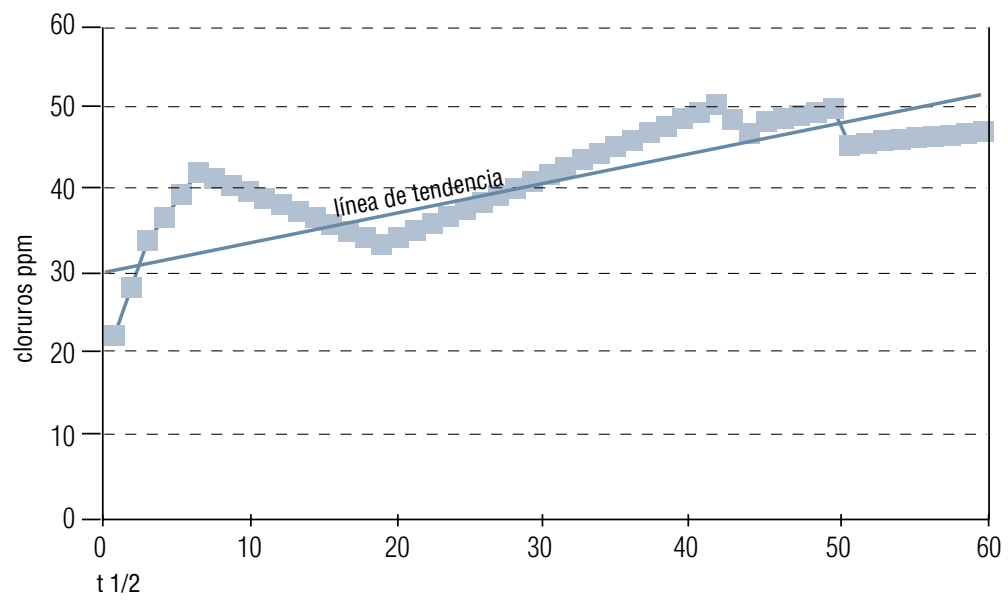

Figura 12. Gráfico de estabilización. $X$ = tiempo transcurrido expresado en raíz cuadrada de días (t1/2). $Y$ = cantidad de cloruros medidos en el baño expresado en partes por millón (ppm). Línea de tendencia lineal y ecuación de cada curva en el gráfico.

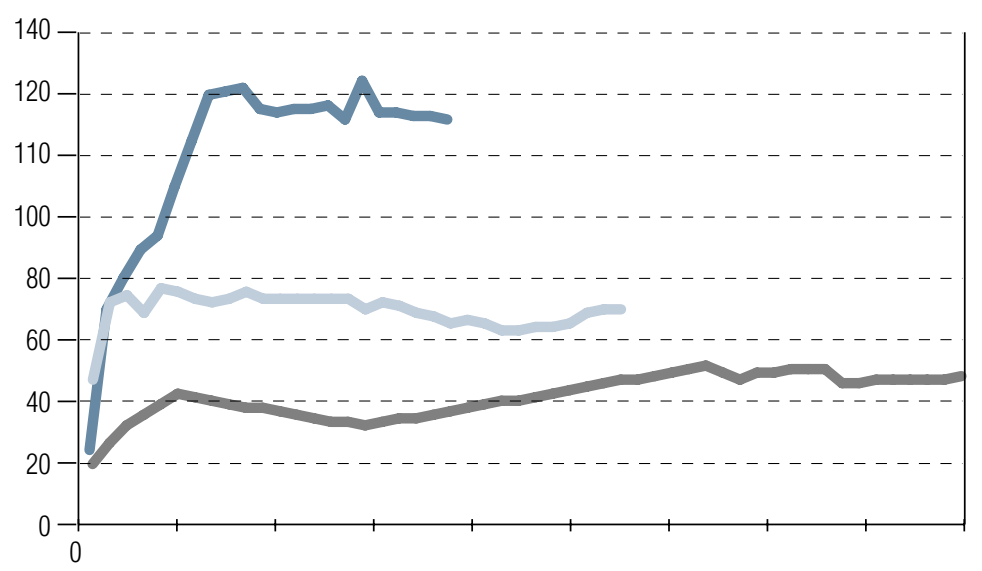

$\longrightarrow$ baño $3 \longrightarrow$ baño $2 \longrightarrow$ baño 1 
0
0
$+\pi$
2
0
0
0
2
0
0
0
0
0
0
0
2
2
0
1
$<$

ba de ultrasonidos durante I minuto siendo posteriormente introducido en un baño de 2500 mililitros de BTA al $1 \%$ en agua desmineralizada dentro de una campana de vacío. Se ha mantenido constante una presión de $60 \mathrm{~cm} / \mathrm{Hg}$. Comprobando que dejaban de fluir burbujas desde los objetos, la impregnación se ha prolongado durante I hora. Posteriormente, las piezas extraídas se han secado por evaporación natural de la disolución en condiciones normales de laboratorio.

Concluido este tratamiento, los objetos han sido barnizado para prevenir la ruptura física de la película de BTA, y su posible contaminación por agentes ambientales y manipulación. La elección del revestimiento protector responde a las características objetivas del objeto y las condiciones del futuro entorno de mantenimiento. Los ensayos realizados por W. Mourey han revelado la eficacia de los revestimientos bi-capa con Rhodopas M, y cera microcristalina para objetos de cobre en ambientes salinos. Puesto que la colección se emplazará en el Museo de Cádiz, se ha considerado esta combinación, de resina y cera para medios salinos, la más adecuada en función de las condiciones teóricas de almacenamiento. Esta decisión viene dada por los altos porcentaje de cloruros y de humedad relativa presentes en las ciudades costeras. Por tanto, la unión de humedad relativa y salinidad ha sido factor concluyente al estudiar la conservación preventiva de estos objetos, frente a otras posibles agresiones como la radiación ultravioleta, los choques térmicos o la contaminación.

La primera fase del revestimiento aplicado ha sido un equivalente comercial del Rhodopas $\mathrm{M}^{\circledR}$, (Mowilith 30) testado por Mourey (Mourey W. 1995), la resina vinílica PVA K 40. Este producto se ha depositado por inmersión del objeto en una disolución al 3\% de resina en acetona. La segunda fase aplicada sobre la resina vinílica se ha realizado igualmente por inmersión del objeto en cera microcristalina disuelta en tolueno al 5\%. La capa de cera depositada adquiere un tono opaco que desaparece mediante un frotamiento suave con cepillos sintéticos accionados por un micromotor eléctrico.

\section{Conclusiones}

En los laboratorios del Centro de Arqueología Subacuática del IAPH se han realizado tratamientos de conservación activa sobre un total de 55 monedas de época bajo-imperial procedentes de prospecciones realizadas en el área de Sancti Petri.

Previamente, la observación visual y el empleo de microscopia electrónica de barrido (SEM) y espectroscopia de energía dispersiva (EDS), han permitido analizar el tipo de productos de corrosión depositados. A partir de este estudio se ha planteado una hipótesis sobre la evolución que sufrieron los procesos de alteración de las monedas a lo largo del tiempo. Pese a que las piezas presentan un cuadro de alteración típico de aleaciones cupríferas depositadas en zonas aerobias, existen pequeñas trazas de productos de corrosión típicos de zonas anaerobias. Estos datos, unidos a los fuertes cambios en la dinámica litoral de la zona, permiten pensar en fases sucesivas de enterramiento y desenterramiento de las piezas.

El tratamiento aplicado sobre los objetos ha permitido alcanzar los objetivos trazados en el proyecto de conservación: "desconcreción" o remoción de las concreciones minerales, y "decloruración" o extracción de aniones $\mathrm{Cl}$-. Si bien, la decloruración tendente a estabilizar los procesos de corrosión no puede considerarse un tratamiento definitivo. Se ha realizado un trabajo intensivo que ha eliminado un gran porcentaje de los cloruros activos presentes en la micro estructura metálica de los objetos. Esta fase del tratamiento unida a la inhibición mediante benzotriazol y los revestimientos protectores de aislamiento permite asegurar un alto grado de permanencia. Sin embargo, para su mayor eficacia, el tratamiento de conservación activa deberá ser complementado con medidas de conservación preventiva. Principalmente, el control de la humedad relativa que es conocido desencadenante de los procesos corrosivos.

\section{Bibliografía}

COTTON, J.B., "Control of surface reactions on copper by means of organics reagents", en Procceddings of the Second International Congress on Metallic Corrosion, New York, 1963, pp. 590-596.

FRANCE-LANORD, A., Bronzes en Ancient Metals. Structure and Characteristcs, ICCROM, 1980, pp. 38-43.

GARCÍA F.., ALONSO C., GALLARDO M., GILES F., BENAVENTE J., LÓPEZ-AGUAYO F., Evolución eustática postflandriense en las marismas del Sur de la Bahía de Cádiz, en Geogaceta, 27, 2000, pp. 7 I-74.

GIULIANI, L. AND BOMBARA, G. An electrochemical study of copper alloys in chloride solutions, En British Corrosion Journal, 5, 1970, p. 179.

GREENE, V., "The use of benzotriazole in conservation", en 4th triennial Meeting, ICOM Committee for Conservation, Venice, 1975 , pp. $\mid-10$.

HAMILTON, D.L. Conservation of Metals, en Conservation of Metals Objects from Undenwater Sites: A Study in Methods, A Joint Publication of the Texas Memorial Museum and Texas Antiquities Committee, 1976, p.33.
MERK, L.E., "A study of reagents used in the stripping of bronzes", en Studies in Conservation, 23, 1978, pp. 15-22.

MOUREY, W. Síntesis de los ensayos sobre los revestimientos de protección de metales (1986-1995), en METAL 95, Proceedings of the International Conference on METAL Conservation. Semur en Auxois, 1995, pp. 225-227.

NORTH, N.A. AND MACLEOD, I.D. Corrosion of Metals en Conservation of Marine Archaeological Objects, Editor: Colin Pearson, Butterworths Ed., London, 1987, pp. 86-88.

NORTH, N.A., Conservation of metals, en Conservation of Marine Archaeological Objects, Editor: Colin Pearson, Butterworths Ed., London, 1987, pp. 236-237.

SKERRY, B., "How corrosion inhibitors work", en Keene, 1985, pp. 5-12.

TYLECLOTE, R.F. Durable materials for sea water: the archaeological evidence, en The International Journal of Nautical Archaology and Underwater Exploration, 6.4, 1977, pp. 269-283. 